treated by conventional treatments, e.g. antidepressants for endogenous depression, neuroleptics for schizophrenia and monoamine oxidase inhibitors for phobic anxiety. In addition, many patients with persistent pain who are not suffering from depression may benefit from tricyclic antidepressant treatment in doses that are usually considered to be subtherapeutic in the treatment of depressive illness. The psychiatrist should also be able to identify features in the history of these patients that may provide the basis for future management. These include adoption of an adult role early in life with insufficient time or opportunity to be dependent on parents, evidence of rejection or physical abuse in childhood, history of excessive activity or hard work antedating the pain by many years, and existence of a crippled relative. With this background, social and marital difficulties are not uncommon.

Although the interpretation of the problems may not be too difficult, subsequent management is more likely to involve behavioural or cognitive methods of treatment, rather than psychotherapy. It has been realized for some years that many patients with chronic psychogenic pain are unable to understand or accept alternative explanations for the origin of their pain which fail to include physical factors. These patients often cannot verbalize their feelings and may be incapable of linking emotions with fantasies-a condition that has been described by the term alexithymia. ${ }^{4}$ It is understandable that patients of this kind are unlikely to be devotees of the psychotherapist's couch.

It is concluded that the psychiatrist plays a more limited role in the pain clinic than might be expected considering the frequency of psychiatric conditions in this population. He can be best used in identifying those patients with definitive psychiatric illnesses, treating those that are likely to benefit from drugs, and referring the remainder to behaviourally or cog- nitively-orientated psychologists. Psychiatric assessment scales for depression can be used as screening instruments and would avoid the psychiatrist having to see every patient attending the clinic. Even this limited service may be unnecessary. A recent survey from the Mayo Clinics showed that although 53 per cent of patients admitted to a pain centre were depressed on admission, only 2 per cent were depressed at discharge, despite receiving no specific pharmacological or other treatment for depression. Ipso facto, unless our psychiatrist is an experienced behavioural or cognitive therapist his skills may be uncalled for in a pain clinic setting.

\section{ACKNOWLEDGEMENTS}

My thanks are due to Dr J. E. Charlton and Professor J. W. Thompson of the Newcastle Pain Relief Clinic for vigorous criticism and helpful comments on the manuscript.

\section{REFERENCES}

iHagedorn, S. D., Maruta, T. Swanson, D. W \& Collugan, R. C. (1984) Premorbid MMPI profiles of low back pain patients: surgical successes versus surgical failures. Pain. Supplement 2, 258.

2Pliowsky, I. \& SPENCE, N. D. (1975) Patterns of illness behaviour in patients with intractable pain. Journal of Psychosomatic Research, 19, 279-287.

JTyrer, S. P., Capon, M. N., Peterson, D. M., Charlton, J. E. \& Thompson. J. W. (1985) The detection of psychiatric illness and psychological handicaps in a British pain clinic population. (Accepted for publication in Pain.)

4Sifneos, P. E. (1973) The prevalence of 'alexithymic' characteristics in psychosomatic patients. Psychotherapy and Psychosomatics, 22, 255-262.

SBrown, M. K., Maruta. T. \& Mchardy, M. J. (1984) Effectiveness of management of chronic pain in the long-term resolution of pain-associated depression. Pain, Supplement 2, 185.

\title{
Policy into Practice in a New Secure Unit
}

\author{
M. Faulx, Department of Psychiatry, Knowle Hospital, Fareham, Hants.
}

Albert Kushlick first showed me this technique. He used it for setting up hostels for the mentally handicapped and I then used it when setting up a Medium Secure Unit. It could be applied to any Unit and I am writing it up because I found that staff members in new units had run into problems where they had not adopted this or a similar approach. The idea is to show how one can translate 'aims' or 'principles' into 'brass tack' practices by design and with consultation in a multidisciplinary setting.

I make the assumption that the consultant in charge (who will be looked to to provide a lead) will, through study and experience, have gained a clear idea of the sort of unit and the sort of attitudes and practices he wishes to see developed. This is probably best obtained by visiting many units and taking from them their best ideas.

The next problem is how to convey these ideas to one's own staff and involve them in the process of finding the best way to do things. In my case I spent considerable time in seminars during a two-month induction period with the newly appointed staff of the Unit, in conveying the principles on which I wished to see the Unit run. Incidentally, I found that I learned a great deal from the staff, which expanded my own ideas. One has then to ask how can these principles be enacted or, more basically, who would do what and when, and who would take and pass on responsibility?

To decide this, the newly appointed staff and myself sat down together through a series of 'policy and practice' meetings. A leader (in our case, myself) acted as a conductor at the policy meetings. The first thing to do is to break the task down to a whole series of 'problems' which can be specified. Thus the task of 'How to create a pleasant environment' is broken down into: 'How do we keep the ward clean?'; 'How do we keep a constant supply of fresh linen?': 'How do we greet and admit a new patient?' etc. Thus these 'problems' vary from 
BULLETIN OF THE ROYAL COLLEGE OF PSYCHIATRISTS, VOL 9, JULY 1985

simple administrative matters to complex human interaction.

Each 'problem' is taken in turn and we decide what our 'aim' is, i.e. what the solution will be. If the 'problem' is 'How do we get fresh laundry?' the 'aim' becomes 'To have a method of acquiring sufficient laundry on a regular basis to meet routine and crisis demands'. We then discuss the matter and air the difficulties that are likely to arise and decide on the actual 'action' to be taken which will achieve this: naming the responsible people, their areas of responsibility, and stating how they will actually carry out their task. Everyone then knows how linen will get to the ward, who will be looking after it and, because it has been discussed by all of us and agreed, there should be little argument about it afterwards.

Further examples will clarify the method which I will set out in the form of 'problem-aim-action'.

Problem: 'What general security and safety measures should be adopted by the Ward?'

What we are trying to achieve would then be discussed in the seminar with all members of the staff. The doctors might express their anxiety about excessive security measures which might be damaging to the patients' health, nurses might express their views both about regimes in which it is safe to look after patients and regimes which would prevent absconding. The psychologists might have contributions to make on the psychological effects of different regimes, and the problems of assessing absconding risks. In my case I spent a great deal of time, supported by some experienced nurses, conveying a philosophy of working with the patients and of avoiding excessive confrontation and unnecessary security. From this a general consensus on the likely dangerousness of patients and the need for security and the means of achieving it, would emerge and the 'aim' would crystallize.

\section{Aim}

To use the minimum of security and safety methods necessary for the safe running of the ward. The discussion which continued would then allow firm guidelines to be stated and written down. perhaps as follows.

\section{Action}

1. Principal security lies in observation of patients, their behaviour and their possessions. Knowledge of their possessions is important, it is also important to know that things are returned (particularly potential weapons).

2. Ward: The Ward entrances will be locked every night from $8.00 \mathrm{pm}$ to 7.00 am (coinciding with the night shift). During the day the Ward will usually be locked so long as there are patients who do not have full parole. If circumstances were appropriate, however, the Nurse in Charge. in conjunction with the doctor, may choose to open the Ward even though some patients do not have full parole.

3. Kitchen: The kitchen is locked during the night and is opened for hourly and two-hourly periods during the course of the day.

4. Bathrooms: Bathrooms should be locked if possible to prevent abuse and for safety reasons, though patients should be given as much access as staff levels permit.
5. Alarm systems: An alarm system of bells will be shared with other wards; nurses may carry whistles to call for help.

6. Nurses will retain the right to search patients' property under the supervision of the Senior Nurse on duty, and in the presence of the patient if possible, should there be reasonable cause (e.g. suspicion of weapons, stealing, etc).

7. Patients who are an unknown entity admitted as emergencies at night will be allocated a secure room which will be locked. Where the patient is known, other approaches can be considered.

8. Parole: Parole status is decided at the ward round, though the Nurse in Charge always has the discretion to alter it.

9. As the patient leaves the Ward, the person who lets the patient out will see that it is recorded. When the patient returns this must also be recorded.

10. The Nurse in Charge must make sure that the Ward is secure during his shift.

11. The Nurse in Charge will check the whereabouts of all patients at $8.30 \mathrm{pm}$.

12. The Nurse in Charge will ensure that after bedtime safety checks are made on all electrical appliances, e.g. cooker, etc.

If this example seems too specialized, consider such 'problems' as: (a) 'What procedures should be adopted for the use of behaviour modification?'; (b) 'What procedures should be adopted if a patient becomes violent?'; (c) 'What procedures should be adopted to assess a patient for admission?' Furthermore, consider such difficult matters as: (a) 'How can the ward provide a therapeutic atmosphere whilst maintaining the security of the ward?', and (b) 'What steps should be taken on admission to ensure that the patient is made as welcome as possible, but still allowing the staff to feel in control of the situation?'

This approach to drawing up a Policy and Practice document clarified, at a very early stage, not only the prejudices and differences of opinion which existed between different staff members about the handling of certain situations, but also actual ignorance about all sorts of procedures. It should be possible by this approach to expose these potential difficulties and decide on a course of action which all can accept.

Thus, in summary, the approach has the following advantages:

1. Each member of staff has the opportunity to bring forward his anxicties and any new ideas.

2. As it is discussed. each 'problem' will reveal ignorance, prejudice and any differences in attitude between staff. It should be possible to reach a course of action which is acceptable to all members so that everyone knows what to do and where they stand.

3. If views between groups cannot be resolved in this setting, it can be accepted by the group that a course of action decided on, although not reaching full consensus, can at least be tried for a set period before review. 